\title{
Perception of Climate Variability and Its Impact by Smallholders in Pastoral Systems of Abudwak District, Galmudug State, Somalia
}

Mohamed Yonis Abdullah ( $\sim$ myunis@snu.edu.so)

Somali National University, Collage of Veterinary Medicine and Animal Husbandry, Somalia Shafii Abdullahi Mohamed ( $D$ Shafii@snu.edu.so)

Somali National University, Collage of Veterinary Medicine and Animal Husbandry, Somalia

\section{Systematic Review}

Keywords: Climate variability, Pastoral Systems, Perception, Impact

Posted Date: January 13th, 2022

DOI: https://doi.org/10.21203/rs.3.rs-1243519/v1

License: (c) (1) This work is licensed under a Creative Commons Attribution 4.0 International License.

Read Full License 


\section{Abstract}

it is true in all the regions of the country; there is no stable and reliable documented meteorological data for reasonable tracking of the climate change and variability. Thus, this study explores the perception of significant variability in climate and related impact on local livestock holders among smallholders in pastoral systems of Abudwak district, Somalia. We drew on empirical data obtained from pastoral communities surveys conducted in 4 villages, 169 pastoral associations. Using this data, this study analyses smallholders' perception of climate variability and its associated impact on local livelihood, and the effect of several household on perception. Respondents interviewed during the study period, however, believed that there has been significant variability in the rainfall and temperature patterns for the last twenty years and considered climate variability as a salient risk to their future livelihoods and economic development. Likewise, the general perception of the people is that both rainfall and temperature have highly been fluctuating for decades now became unpredictable with less rainfall in shorter duration and warmer temperature over year now than usual. Different levels of perception were expressed in terms of climate variability and the impact on traditional rain-fed. Age, education level, livestock holding, access to climate information and extension services significantly affected perception levels.

\section{Introduction}

Perception strongly affects how agriculturalists react with climate-induced hazards and chances, and the precise nature of their behavioural reactions to this perception will shape adaptation options, the process elaborate and adaptation outcomes (Adger et al. 2009; Pauw 2013). Misconception about climate variability and its associated risk may result in no adaptation or maladaptation thus increasing the negative impact of climate change (Grothmann and Patt 2005). Omosa (2005) research to that zones in Somalia peak affected by climate variability are the arid and semi-arid, states that these areas found $80 \%$ of Somalia's land mass and support $70 \%$ and $25 \%$ of the nation's livestock and human populations, respectively. These areas obtain yearly rainfall of under $500 \mathrm{~mm}$ and its delivery within the seasons is usually random. Livestock production are the major economic activity directly depending Pastoral societies and climate variability appears globally extreme weather events have already impacted on the livelihood activities of pastoralist in significant and uncertain ways. Somalia average surface temperatures have increased by an estimated $0.3^{\circ} \mathrm{C}$ between 1900 and 2005 (Ehrhart, 2006). The vulnerability of Somalia pastoralists to climate variability comes both from being predominantly located in the ASAL, and from various socio-economic, demographic and policy trends, limiting their capacity to adapt to climate variability (IGad, 2010). However, in the last 30 years the climates in Somalia has been variable and have not available studies that investigated effects of climate variability on livestock productivity. In order to adopt these variations communities must first receive that the climate is variability, understanding on impacts and then adapt.

\section{Research Methodology}




\subsection{Description of the Research Area}

This study was conducted among pastoral households in Abudwak District. Elevation above the earth 329 metres ( 1,079 feet) and located at latitude $6.2419^{\circ}$ and longitude $46.225^{\circ}$. The city generally features warm winters and semi hot summers. The district of Abudwak is located in northwest of Galgadud region in central Somalia. It is one of the eight districts in the region. Galgadud is the nationally recognised region with its headquarters in Dhusa-Mareb. The city of Abudwak is believed to be the largest commercial city in the whole of Galgadud region. It shares a borderline with the Somali region of Ethiopia. According to the locals, the population of the district is roughly around 220,000 including surrounding villages but UNDP puts the population number around 41,500. Most of these people are pastoralists herding camels, cattle and goats. Abudwak and surrounding area is red sandy with semi desert look, Further into the grazing lands near the border with Ethiopia's Somali Province, one finds forest and mountains where mostly camels are herded. The city's population has increased due to influx of people that fled from the fighting around the District.

\subsection{Research design}

The study adopted a cross sectional survey to provide numeric description of trend in attitudes and opinions of the pastoralist in the Abudwak District. A cross sectional survey is the best method of choice if you want to gather data at one point in the short time. A descriptive research approach was employed in order to collect both qualitative and quantitative.

\subsection{Study Population}

The study population consisted of 300 Households Pastoralists by (Local Authority, 2021), around Abudwak district. There are 105 pastoral communities' around Abudwak District, 95 Pastoral communities from Shiilamadow village, 50 pastoral communities from Ari cadeys village and 50 pastoral from Ballikibir village. This target population was selected because they were directly affected by climate variability in Abudwak District.

\subsection{Sample Size and sampling technique}

The sample size consisted of 169 Pastoral households from population of 300 Pastoral Households in Abudwak District. The sample was determined according to (Krejcie and Morgan tables of sample, 2013). Krejcie and Morgan (1997) recommended a sample of 169 for population of 300 at $95 \%$ level of confidence, 0.05 level of significance and $5 \%$ margin of error. Hence, 169 households were selected for this study based on these recommendations.

\subsection{Data Collection Methods and Tools}

A household survey interview was used to collect data mainly from pastoralist using field observations, household survey questionnaire, key informant interviews, and focused group discussions. 
Household survey, Household survey was used to generate primary data from the sample households. Enumerator administered questionnaire was employed to generate information from the sample households drawn from the population in each village. The major issues which were addressed in the household survey include household demographic characteristics, information about the perception of temperature and rainfall variability, and its impact on their livelihood and adaptation strategies. To carry out the $\mathrm{HH}$ survey questionnaires, close ended questions were prepared in English languages and then translated into local language (Somali), for avoiding confusing with respondents and as the majority of the respondents are Somali speakers.

Key informant interviews, The key informant interview was conducted from representatives of different stake holders who have a good knowledge about the biophysical conditions of the area and hence local leaders of the villages, Governmental Institution Agents, development agency, active woman in local community and model pastoralists were used as key informants. The important issues included in this interview were the past and present temperature and rainfall I variability and its impact.

Focused group discussions, The main purpose of the focused group discussion was to get insights on and understand about the perception of the temperature and rainfall variability, its impacts and their responses to the variability induced hazards. The major discussion topics are households understanding of temperature and rainfall variability and its cause, their impacts and adaptation strategies they were used and barriers to employ them effectively. The discussion was carried out among groups classified by sex, age and economic status of people. At each village, one separate focused group discussion was carried with elders, women, and youth groups. There were a total of four FGDs in different place and each group has comprised 8-12 participants.

\section{Data Analysis}

Quantitative and Qualitative data derived from the household interviews were analyzed the Statistical Package for Social Sciences (SPSS) software. To document the pastoral perception community perception, or climate variability, effects and adaptation was done and descriptive statistics such as percentage and tables used to present the results.

\section{Results And Findings}

\section{Demographic Characteristics of the Respondent}


Table 3.1

Demographic statistics of the respondents in Abudwak District $(n=135)$

\begin{tabular}{|ll|}
\hline Variables & Percentage \\
\hline Relationship with head of household & \\
\hline Head & $60 \%$ \\
\hline Spouse & $36.2 \%$ \\
\hline Mother & $1.48 \%$ \\
\hline Father & $2.2 \%$ \\
\hline Sex & \\
\hline Male & $37.3 \%$ \\
\hline Female & $62.7 \%$ \\
\hline Age & \\
\hline $20-34$ & $5.1 \%$ \\
\hline $35-44$ & $11.8 \%$ \\
\hline $45-54$ & $53.7 \%$ \\
\hline Above 55 & $19.2 \%$ \\
\hline Marital Status & \\
\hline Married & $79.2 \%$ \\
\hline Widow & $14.8 \%$ \\
\hline Divorce & $5.9 \%$ \\
\hline Level of Education & \\
\hline None & $11.2 \%$ \\
\hline Primary & \\
\hline
\end{tabular}

Results from table 4.1 indicate that majority $60 \%$ of the respondents were heads of the household while $36.2 \%$ where spouses. This has significant implications on household livelihood activities. Given that it's the responsibility of the male to provide for their families. It also indicates that it's the male that dominantly manage households.

In most of their households, $38 \%$ were male while $62 \%$ were respondents female. The large numbers of female as heads of the households could be explained by the fact that the women are strong than the 
males, women's are fallows goats and selling milk around the village where mostly male of the household heads are absent from the city.

The results also indicate that most $63.7 \%$ of the respondents were aged between $45-54$ years, while $19.2 \%$ of the respondents were aged above 55 years and only $11.8 \%$ of the respondents aged between 34 44 years. This indicates that most of household headed were mature and productive status of their household livelihood activities. Majority of the respondents are mature have ability to produce livelihood assets and had the responsibility to feeding their family. Table 4.1 also shows the distribution of respondents by marital status. It shows that most $79.2 \%$ of the respondents were married while 14.8 were widow and only $5.9 \%$ were divorced.

When asked about their sources of income/occupation, $76 \%$ reported to be pastoralist while $24 \%$ derived their income from casual labor. With regard to education, the result revealed that majority $88.8 \%$ of the respondents had no formal education, while 11.2 had primary and formal education. This shows that most households around villages from Abudwak district are headed by people without education. This finding concurs with Caleb (2006) who found that $77 \%$ of total populations in Turkana Central district of Kenya were illiterate. This low level of literacy has significant negative implication in coping with climate change in their locality. Further, Table 3.1. clear shows the level of education of the respondents. It shows that majority $88.8 \%$ of the respondents had no formal education, while $11.2 \%$ had primary and formal education level of education respectively. This shows that most households around villages Abudwak district are headed by people without any formal education. Lack of education can decrease their skills and approaches to earn household livelihood activities.

\subsection{Income sources/Livelihood}

In order to understand the effects of climate variability among pastoralist communities in Abudwak District, it was important to first understand the sources of income or livelihood activities as this has a bearing on how they perceived climate variability impact or effect

(Table 4.4).

\begin{tabular}{|ll|}
\hline Income source/livelihood & Percentage (\%) \\
\hline livestock productivity & 62.6 \\
\hline Casual Labor & 20 \\
\hline Remittance & 17.4 \\
\hline
\end{tabular}

Majority (62.6\%) of the respondents were depending on sales of livestock production as a source of their income while the remaining $20 \%$ were running casual labor as a source of their income. Further, $17.4 \%$ of the respondents demonstrate to get external income from their nearest family living outside the country or their politicians who live in the capital city of the Mogadishu. Main sources of income of pastoral 
community's around Abudwak district are livestock raring. Other communities separated livestock in one area due to climate variability and preferred may be livestock raring as a kind of sources of their income and strategies for sustain their livelihood activities. Pastoralist in Abudwak district also have temporary source of income for casual labor like building houses or other activities for daily based work in the town of the city. Another hand worked for INGO's or LNGO's ongoing projects like cash for work, food for work, conditional cash transfer or unconditional cash transfer to feeding their lives and their families. This study is connected with Silvestri, et al. (2012) his findings showed livestock systems play an important role in the livelihoods of many rural communities in Africa.

FGD- In normal times, the main source of income is livestock products and sale of livestock. Some of the locals depend on remittance from abroad and on commercial business. However, as the food security deteriorated, thousands depending on livestock resources are drastically affected. The middle and poor income groups in Abudwak are suffering from asset depletion - selling off major immovable assets like land. Food aid is rarely delivered due to insecurity in the area. Pastoralists groups seem to depend on hand outs from better off relatives. This is followed by borrowing food on credit.

\subsection{Perceptions of climate variability around Abudwak district}

The study findings reveal that there is climate variability in Abudwak district and that local communities are aware of climate variation and impacts. The communities stated that climate has changed and as a result droughts have become more frequent and prolonged Figure 4.1.

The results also indicate that $38 \%$ the community perceived the rains to the reduced.

According to the local communities the long rains used to occur in the month of April but for the last 20 years they occur little and only in the month of June, although sometimes they might come late or fail to come altogether. The rainfall is erratic, and when it comes most of it and then disappear over a few days or hours causing long time of dry season. Despite, seasonal changes also happened for the last decades in Abudwak district. The facts that demonstrated changes in seasonal was change period of days increased hot days, long period of winter and summer and short period of spring and autumn. Seasonal changes created long period of days and short time of period of days. Weather and climate variability defined four seasonal changes in nature but climate change for human activities caused to period and duration of days and nights.

Focus group discussants agreed that there has been a change in climate patterns. According to them, this observation was supported by a one of the participants in his fifties who was born and brought up in Shiilmadoow village. He described the change in climatic pattern using the following statement. 
I am a pastoralist in Shiilmadoow village. I was badly affected by the drought in the area. I owned 28 camels, 16 cows and 135 goats. I also had a berked as a water source. The berked is dry and i moved away from it. There was some pasture there but i could not truck water there because it is expensive. Here i moved close to the borehole. But what is sense... nothing because there is no pasture, only water you get with difficulty. You see how my hut looks. I fed them with the animals. Not all animals but the ones i love. I didn't want to lose them. They are of a good breed. What else can i do? Some of them have already died. This is a natural disaster. I lost 13 cows, 31 goats and 2 camels. They have died. The rains are not near. I fear I may lose more. The camels are getting weaker each day. So are the remaining shoats. It is bad luck. I am slowly becoming poor, very poor. I cannot continue keeping my children..... What else will i do if lose my animals. No problem Allah will help us, the result is consistent with Tallaksen et al. (2009) findings which indicates that droughts are perceived as a natural occurring.

This result is in line with Devereux (2006) finding which shows that droughts were part of normal life cycle in arid and semi-arid areas, where rainfall is low. "Severe and prolonged drought has affected the water levels of water reservoir and bore holes arround Abudwak district". They were thus in agreement with the following statement from one of them who stated that: "When we were growing up, bore holes is available whole the year and we were not worried any dry season and lack of water single season, because have a lot of water. During heavy rains they used to overflow all over the water body and increased infiltration of water in the water table. Today even if there is heavy rain washed away soil fertility and reduced amount of water infiltration and do not overflow as they used to do in the past. The water levels of our underground level decreased and have gone down by $60 \%$ ". This result is in line with, Webb and Braun (1994) who found that the eastern lowlands of Ethiopia are vulnerable to drought and there have been notable droughts in this part of the country throughout human history as a result result of Increase in temperature and rainfall variability, associated with global climate change, are likely to further increase the drought risks.

\begin{tabular}{|c|c|}
\hline Year & Description of drought \\
\hline 2000 & there was a severe drought while affected livestock production \\
\hline 2002 & $\begin{array}{l}\text { there was a drought causing of water reservoir but forage and pasture for livestock is } \\
\text { available }\end{array}$ \\
\hline 2005 & there was a severe drought causing of water and also pasture \\
\hline 2008 & there was a severe drought and people ate yellow maize \\
\hline 2011 & $\begin{array}{l}\text { there was a drought that caused death for people and livestock and crop production at } \\
\text { all }\end{array}$ \\
\hline 2013 & there was a drought and so many livestock died \\
\hline $\begin{array}{l}2016- \\
2017\end{array}$ & $\begin{array}{l}\text { There was a drought is called (Sima) means it affected as same for whole lands of } \\
\text { Somali community in two years of consecutive. }\end{array}$ \\
\hline 2021 & There was a drought and it killed many livestock \\
\hline
\end{tabular}

FGD discussants elaborated the aforementioned further by giving the trend of droughts for a period of 20 years as shown below: seasons of certain flowering plants, and the prevalence of certain insects, birds 
and diseases.

\subsection{Perceived Causes of Climate Variability}

Respondents in the study area were asked on what they perceived as the cause of climate variability. They attributed climate variability to three factors as shown in Table 4.3 specifically, $71.1 \%$ of the respondents attributed it to human-made factors, $28.9 \%$ to natural factors.

Table 4.3

- Perceived cause of Climate Variability (135)

\begin{tabular}{|ll|}
\hline Cause of climate variability & Percentage (\%) \\
\hline Human Made & 71.1 \\
\hline Urbanization & 0.7 \\
\hline Natural & 28.2 \\
\hline
\end{tabular}

Presents human-made activities associated with climate variability as given by the respondents. Most of the respondents stated that human made are main factors caused change of climatic when they cutting down trees for building purposes as well as clearing bushes to lay concrete on way for settlement and other economic activities had caused climate variation.

Humans have caused many changes on the planet through land use changes by clearing trees which are valuable carbon sinks, to make room for urban developments, human settlement and agricultural activities. By removing these valuable carbon sinks global warming is being hastened. The respondents indicated that climate variability was caused by industrialization although they had limited knowledge of the relationship between the two. However, large herds of livestock are very destructive to the environment as the existing resources are exposed to intensive grazing for extended periods of time or without sufficient recovery periods. This has reduced the usefulness, productivity and biodiversity of the land and is one of the causes of desertification and erosion that leads to happened climate variation in Abudwak district.

\subsection{Perceived effects of climate variability in Abudwak District}

Climate variation in Abudwak district effected pastoral main livelihood activities. Pastoralists tend to sale their livestock numbers during droughts out of anxiety and to provide food for their families.

Unfortunately, during droughts livestock become wasted and do not attract competitive bids because buyers do not wish to take risks. However, different challenges and problems created climate variability into livelihood activities for communities such as food insecurity, disease spread and human health problems this entire dangerous situation was the result of climate variability and change of climatic. Loss most of their livelihood activities and rely for survival such as subsistence farming for daily based livelihood activities depend on due to frequent drought and uncertain weather caused loss of agricultural 
production. Furthermore, livestock production decreased loss of available forage and pasture when it became dry season whole the year or more than one year recurrent drought with no raining led to body condition and value of livestock decreased their price and also production. Effect of climate variability on livelihood activities among pastoral communities to created new face of live like poverty, IDP's and internal conflict among them when it the resources scarcity such water shortage, food insecurity and limited sources of income or livelihood activities caused conflict and unrest.

Table 4.5

shows Perceived Effect of climate Variability $(n=135)$

\begin{tabular}{|ll|}
\hline Variables & Percentage \\
\hline Livestock disease & 21.5 \\
\hline Livestock death & 34.8 \\
\hline livestock disease and death & 43.7 \\
\hline
\end{tabular}

Majority (43.7\%) of the respondents were agree failure of livestock production due to climate variability and livestock death with prolonged drought caused shortage of water and lack of pasture and forage to feeding. While the remaining (34.8\%) of the respondents believed more dangerous for livestock effected for drought and other effect caused climate variability. Further, $21.5 \%$ of the respondents demonstrate livestock disease for is a front line for climate variability effect.

Focus group discussants in their opinion about effect of climate variability on livelihood activities and state this statement:

"Droughts had caused fluctuations in the livestock population through increased mortality and reduced birth rates due to decreased forage and lack water availability effected rainfall agricultural dependent and all Abudwak pastoralists are depending on rainfall for rearing animals".

One of the pastoralism from Ari cadeys "I learnt livestock keeping from my parents and I have been doing it since I was a child. In those days, there was grass all over. But over the years, everything has changed. There is no more grass for our livestock. The little rain that falls in this area has become less frequent and sometimes it does not rain at all. Even when we move to new pastures, grass is increasingly hard to find. This change of the weather has an effect on our livelihoods activities. Twenty years ago, we had more than 500 goat and sheep; today, there are just 40 left. I am very worried about this because for us goats are very important. Other hand I was discontinued to cultivate crop and cereals due to frequent drought and uncertain climatic pattern".

\section{Conclusion}

The findings from this study showed that pastoralist in the study area have already perceived the climate variability incidence. They believed that climate variability were increased over the last two decades. In addition there had been irregular and fluctuating rainfall and temperature patterns both spatially and temporarily. It was characterized by declining in amount and its duration was low, whereas, the temperature was warmer throughout the year. The study showed that the impact of climate variability 
among pastoral communities normally manifests itself in the form of livestock losses, which adversely affects the provision of subsistence income, and other socio-cultural goods and services to pastoral households. Pastoral communities in the study villages have been living with the expectation of drought for a long time. They have been suffering, and arguably and increasingly suffer substantial losses in capital and household savings. Most of the household respondents reported that they have experienced drought impacts with varying degree over years. Similarly focus group discussions and key informants were asked about the situation of climate variability like drought occurrence for the last two decades in the study area and most of them indicated that high frequency of drought were experienced in recent years which were not familiar before and it has negative effect on the livelihood of agro-pastoralists in the study area.

\section{Recommendations}

1. The need for a strong and organized early warning system is crucial for the agro-pastoralists to get information about the upcoming weather shocks and take actions accordingly to minimize the disaster as early as possible. This should be supported by proper weather forecast and quantitative data from meteorological stations. Thus, it is needed to establish the meteorological station in Abduqwak district in order to provide reliable and timely weather information on a daily basis.

2. Droughts are perceived as extreme events in climatic systems, whereas in reality they need to be recognized as normal occurrences. They have occurred many times already and will continue to occur. Yet, due to growing water needs, their adverse consequences are likely to increase in the future. Therefore, this study suggests the government to develop a clear policies and strategies to deal with droughts.

3. The ministry of Agriculture of Galmudug and their Partners, as the responsible institutions for provision of met services and Early Warning Systems (EWS), should provide pastoralists simple and understandable (Somali language), timely and reliable weather forecast information to facilitate early intervention by the government and its partners.

4. There is need for the government to strengthen the autonomous adaptation processes of the pastoralists to improve their capacity to cope with and recover from drought. The pastoralists have local communal and household strategies that they use to manage drought and such mechanisms need to be recognized by the government in planning and policy formulation and implementation.

5. Most of the communities of the study area are depending on to use of charcoal as an energy source. So it important to get an alternative source of energy to save for environment and to improve knowledge of droughts for agro-pastoral communities with regard to their environmental and socioeconomic impacts.

\section{Declarations}

Acknowledgements We would like to express our deepest appreciations to Somali Agriculture Technical Group for their financial support. 
Authors' contributions The first author designed data collection tools, gathered primary data and analyzed the data. The Second author was involved in data analysis, interpretation and Grammar correction. Both authors read and approved the final manuscript.

Availability of data and materials The data that support the findings of this research can be obtained from the authors up on request.

Competing interests The authors declare that they have no competing interests.

Ethics and Consent The ethical review committee of Somali National University, Galmudug, Abudwak, Somalia, approved our study protocol and procedures. Informed consent was obtained from all participants.

\section{References}

Adger N, Dessai S, Goulden M, Hulme M, Lorenzoni I, Nelson R, Naess O, Wolf J, Wreford A. Are there social limits to adaptation to climate change? Climatic Change. 2009;93:335-354.

Grothmann T, Patt A. Adaptive capacity and human cognition: The process of individual adaptation to climate change. Glob Environ Chang. 2005;15:199-213. doi: 10.1016/j.gloenvcha.2005.01.002.

Ehrhart, U. I. (2006). Drier summers cancel out the CO2 uptake enhancement induced by warmer springs. National Academy of Sciences of the United States of America, 102, (10), 823-1082.

FAO, (2017). Agriculture and the Food System. Washington, DC: Resources for the Future.

Finderlaro, T. G. (1998). Public attitudes toward construction of new power plants. Public Opinion Quarterly, 73, (3), 566-577.

IGAD, (2010). Time-dependent response of the global ocean to climatic and anthropogenic forcing. International Journal of Science and Environment, 5, (10), 32-32

IPCC, (2007). Potential ecological distribution of alien invasive species and risk assessment. Journal of Conservation Biology, 18, (6), 1504-1514.

Khalil, W. L. (2013. Report of the NOAA Panel on Contingent Valuation. Federal Register Journal, 58, (19), 4601-4614.

Krejcie and Morgan (1970).

Omosa. E. F. (2005). Penetration of a warming signal in the world's oceans: Human impacts. Environmental Science Journal, 309, 284-287.

Paul, D. J. (2007). Climate change and urban children: Impacts and implications for adaptation in lowand middle-income countries. Environment and Urbanization Journal, 20, 501-519. 
Figures

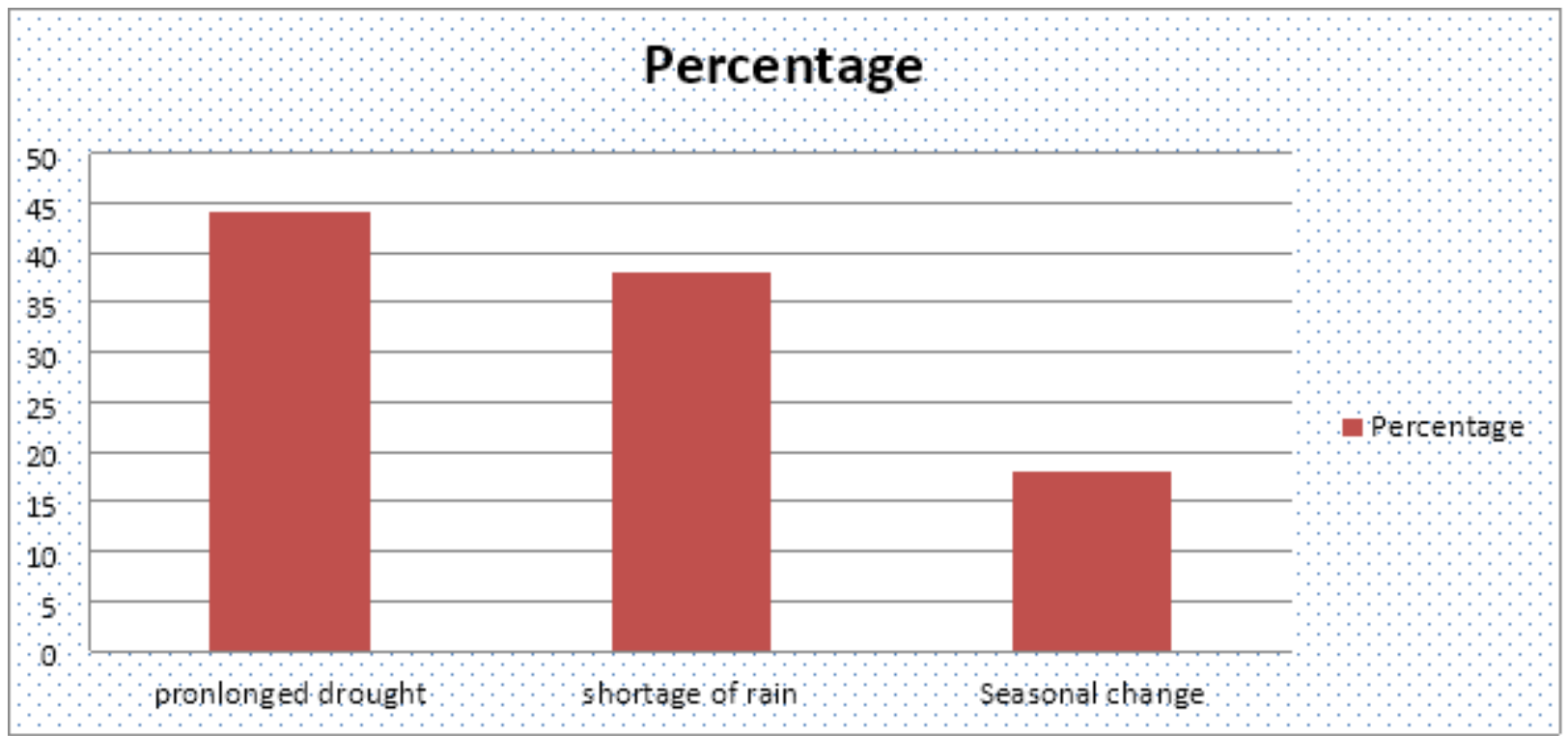

Figure 1

Figure 4.1: shows climate variation in the last 20 years from 2001-2022 